\title{
A MEDICALIZAÇÃO GROTESCa da VIDA NA RUA
}

\author{
The grotesque medicalization of homelessness
}

\begin{abstract}
Resumo: Nas últimas décadas, a intervenção sobre a vida na rua tem vindo a assumir um caráter crescentemente medicalizado, formatando-a como uma questão de anormalidade neuro-psiquiátrica individual. Com base na observação direta de diversos tipos de interações da vida na rua são discutidos vários exemplos da medicalização de condutas de sujeitos sem-abrigo. Estes deixam claro que medicalizar a vida na rua é um procedimento intrinsecamente "grotesco", no sentido que Foucault confere ao termo, referindo-se a uma maximização dos efeitos de poder que parte da desqualificação fundamental de quem o exerce e dos seus enunciados.
\end{abstract}

Palavras-chave: Grotesco; Medicalização; Poder; Vida na rua.

Abstract: In the last decades, intervention on homelessness has increasingly assumed a medicalized form. This frames this phenomenon as an issue of neuropsychiatric individual abnormality. Based on the direct observation of different kinds of interaction, this article discusses several examples of the medicalization of homeless individuals' conducts. These malke clear that the medicalization of homelessness is an intrinsically "grotesque" process, in the sense that Foucault gives to this term, by which he refers to a maximization of power effects that originates from the fundamental disqualification of those who exercise this power and of their statements.

Keywords: Grotesque; Homelessness; Medicalization; Power.

Introduçãon

Desde a década de 1980, no Ocidente Norte, a intervenção sobre a vida na rua assumiu progressivamente uma forma

\begin{abstract}
1 Este texto resulta das investigações que realizei na Faculdade de Economia da Universidade de Coimbra para obter os graus de mestre e de doutor em sociologia. Partes do texto são versões revistas da minha tese de doutoramento, cuja realização que contou com o acolhimento científico do Centro de Estudos Sociais da Universidade de Coimbra e foi financiada pela Fundação para a Ciência e a Tecnologia com a bolsa individual de doutoramento SFRF/BD/85867/2012. Agradeço a Sílvia Portugal, Fátima Alves, Luciana Caliman e Tiago Ribeiro pela leitura de uma versão anterior deste texto e pelos seus comentários. Todos os problemas que permaneçam são da minha responsabilidade.
\end{abstract}

90 | Pensando - Revista de Filosofia Vol. 10, № 19, 2019 ISSN $2178-8437$ 
medicalizada, sobretudo, psiquiatrizada.2,3 As orientações mais ou menos punitivas e penalizadas, que até aí eram dominantes, não desapareceram, mas tendem a articular-se com a medicalização. Deste modo, os procedimentos de intervenção tendem a dirigir-se a um sujeito fundamentalmente inferior que importa normalizar através do internamento psiquiátrico, da frequência de consultas de psiquiatria e psicologia ou da toma de medicação psiquiátrica. As condutas dos sem-abrigo não deixam de ser percebidas como discordantes da normatividade jurídica e/ou sociocultural (não escrita mas transmitida, incorporada e lentamente modificada na sucessão das gerações) dominante mas, tendencialmente, passam a ser intervencionadas através de relações, procedimentos e atores que, de forma ideal típica, visam a sua normalização, transformando-se em questões de doença e/ou deficiência mental com as quais importa lidar medicamente.

Uma das dimensões da medicalização da vida na rua é o seu caráter grotesco.4 Este conceito, introduzido por Michel Foucault no curso Les anormaux, lecionado no Collège de France, em 19741975, mas não explorado posteriormente pelo autor, expressa um exercício de poder que, por estatuto, possui a capacidade de gerar efeitos de realidade que a sua "qualidade intrínseca" não deveria conferir.5 Os procedimentos da medicalização da vida na rua revelam-se grotescos, sobretudo, na medida em que tendem a

2 GOWAN, Teresa. Hobos, Hustlers and Backsliders: Homeless in San Francisco. Minneapolis: University of Minnesota Press, 2010. HOPPER, Kim. Reckoning with Homelessness. Ithaca: Cornell University Press, 2003. LOVELL, Anne M. "Classification and its Rislks: How Psychiatric Status Contributes to Homelessness Policy". In: New England Journal of Public Policy, vol. 8, n. 1, 1992, pp. 247-263. LYON-CALLo, Vincent. Inequality, Poverty and Neoliberal Governance. Toronto: University of Toronto Press, 2008 [ed. orig.: 2004]. MATHIEU, Arline. “The Medicalization of Homelessness and the Theater of Repression". In: Medical Anthropology Quarterly, vol. 7, n. 2, 1993, pp. 170-184. WASSERMAN, Jason Adam; CLAIR, Jeffrey Michael. At Home on the Street: People, Poverty \& a Fidden CuIture of Homelessness. Boulder e London: Lynne Rienner Publishers, 2010.

3 Os argumentos apresentados neste texto ancoram-se na observação direta de interações e processos decorridos em Portugal. A forma específica dos processos de medicalização da vida na rua observados não pode ser transposta para outros espaços-tempo, incluindo o Brasil contemporâneo, sem sérios cuidados metodológicos. Ainda que, no Ocidente Norte, a medicalização surja sempre articulada com outros processos de governo da vida na rua, a medicalização é, neste espaço-tempo, uma dimensão fundamental das relações de saber-poder que caracterizam a vida na rua. É argumentável que a medicalização tem um peso relativo inferior nos processos de governo da vida na rua no Brasil, mas apenas uma reflexão comparativa e ancorada na praxis de ambos os espaços-tempo poderia avançar esta discussão, estando isto fora do propósito deste texto. Fica a cargo de cada leitor/a avaliar qual o valor heurístico dos argumentos aqui apresentados para a compreensão da vida na rua no Brasil.

4 Uma análise detalhada da medicalização da vida na rua permite observar que este processo parte de diferentes intencionalidades e produz efeitos variados. Estas encadeiam-se de forma conflitual ou harmoniosa consoante o momento e o espaço concretos em que se efetivam. Nenhuma intenção individual subjetiva e reflexiva tem capacidade absoluta para orientar este encadeamento. Mas a interação das diferentes operações medicalizantes gera um plano estratégico da ação coletiva das instituições da intervenção que, sem negar a multiplicidade, se apresenta como um padrão global da medicalização da vida na rua. Este texto foca-se em exclusivo no grotes co da medicalização, considerando-o como uma característica entre outras, ainda que se trate de uma característica central da medicalização da vida na rua sem a qual este processo não pode ser compreendido de modo adequado.

5 FOUCAULT, Michel. Les anormaux: Cours au Collège de France, 1974-1975. Paris: EHESS, Gallimard, Seuil, 1999.

91 | Pensando - Revista de Filosofia Vol. 10, № 19, 2019

ISSN $2178-843 x$ 
partir de interpretações patológicas daquilo que os sem-abrigo fazem e dizem (em rigor, daquilo que eles são) que são desancorados da praxis da vida na rua, não impedindo isto que gerem efeitos de realidade constrangedores sobre as vidas destes sujeitos. Esta falta de ancoragem praxiológica dos procedimentos patologizantes manifesta-se, simultaneamente, na ausência de compreensão das propriedades estruturais da vida na rua e na descontextualização de cada experiência biográfica da vida na rua.

Neste texto, a reflexão sobre esta faceta da medicalização da vida na rua ancora-se no trabalho de observação direta que realizei numa cidade portuguesa de média dimensão, entre 2010 e 2014, para as minhas investigações de mestrado e de doutoramento.6 Ao longo deste período, estive presente em diversos momentos de contacto entre sem-abrigoz e profissionais de instituições que com eles trabalham quotidianamente, bem como noutras interações em que os primeiros ou os segundos estavam ausentes. Entre as situações em que estavam ausentes sem-abrigo, em 2013 e 2014, assisti com regularidade a reunióes interinstitucionais em que estavam presentes representantes de diversas instituições assistencialistas e psiquiátricas com o propósito explícito de coordenar a intervenção sobre a vida na rua na cidade em que decorreu o trabalho empírico da minha investigação. Nestas, era claramente preponderante a mobilização de grelhas de leitura e formas de ação medicalizadas. Com base neste campo, discuto alguns exemplos claramente grotescos da intervenção medicalizada sobre a vida na rua. Diversos profissionais de instituições assistencialistas (públicas e privadas) e do dispositivo psiquiátrico definem uma grande parte das condutas de sem-abrigo como indicadores de

6 ALDEIA, João. "A barraca do Ruin: Os laços sociais no fenómeno dos sem-abrigo. 2011. Dissertação (Mestrado em Sociologia) - Faculdade de Economia da Universidade de Coimbra, Coimbra. ALDEIA, João. Governar a vida na rua: Ensaio sobre a bio-tanato-política que faz os sem-abrigo sobreviver. 2016. Tese (Doutoramento em Sociologia) - Faculdade de Economia da Universidade de Coimbra, Coimbra.

7 Ancorando-se num caso de Portugal, o texto usa o termo sem-abrigo, mais habitual neste país, em detrimento da designação população em situação de rua, mais frequente no Brasil. Contudo, convém ter em mente que estas duas designaçốes não são totalmente coincidentes. Enfatizando o contexto (a situação) em detrimento da subjetivação desqualificada (a vida na rua), a noção de população em situação de rua torna mais fácil invisibilizar que a vida na rua é inextricável de uma desqualificação político-ontológica extrema da qual é estruturalmente difícil os sem-abrigo afastarem-se. Nenhuma das designações é ideal mas o termo sem-abrigo, sendo tomado como substantivo mais do que como adjetivo, tem a vantagem heurística de ser incapaz de se libertar narrativamente da brutalidade político-ontológica da praxis da vida na rua. Tal como, para Arendt, no período entre as duas Guerras Mundiais, o drama dos apátridas era o facto de serem tornados humanos e nada mais do que humanos, no Ocidente Norte contemporâneo, o drama da vida na rua é o facto dos sem-abrigo serem tornados sem-abrigo e nada mais - assim perdendo as salvaguardas jurídicas, éticas e económicas que são garantidas aos sujeitos que, graças às suas posições estruturais privilegiadas, são coletivamente construídos de facto (e não meramente de jure) como cidadãos e pessoas por inteiro. Cf. ARENDT, Hannah. As origens do totalitarismo. Alfragide: Dom Quixote, 2010 [ed. orig.: 1951], pp. 353-401, em particular, p. 394. Desenvolvi este argumento em ALDEIA, João. Governar a vida na rua: Ensaio sobre a bio-tanato-política que faz os sem-abrigo sobreviver. 2016. Tese (Doutoramento em Sociologia) - Faculdade de Economia da Universidade de Coimbra, Coimbra.

92 | Pensando-Revista de Filosofia Vol. 10, № 19, 2019 ISSN $2178-843 x$ 
anormalidade biomédica individual. Para estes profissionais, poucas coisas podem ser ditas e feitas por quem vive na rua que não sejam passíveis de indicar uma perturbação neuropsiquiátrica destes sujeitos que, em si mesma, explica o facto de serem sem-abrigo e todos os problemas com que se deparam ao longo das suas vidas.

\section{A medicalização da vida na rua}

No modelo societal moderno ocidental contemporâneo, desde a década de 1980 , a intervenção sobre a vida na rua - em rigor, sobre cada um dos corpos individuais que vivem na rua - é profundamente medicalizada. A cosmologia, a forma de leitura do mundo e de enunciação de verdade sobre ele, de origem médica mental é uma parte fundamental dos processos de decisão e ação da intervenção sobre a vida na rua. Os profissionais das instituições assistencialistas públicas e privadas - mas também vários sujeitos domiciliados não diretamente envolvidos na intervenção - guiam-se, em grande medida, por representações, enunciados e procedimentos de origem upsin, sobretudo, neuropsiquiátrica e psicológica.8

A característica definidora de um processo de medicalização é a extensão de uma cosmologia de origem médica à totalidade ou quase-totalidade do campo social de um fenómeno, passando os seus atores a mobilizar discursos, definições, enfim, toda uma semântica médica para o abordar.ı $A$ expressão "s"medicalização" descreve um processo pelo qual problemas não-médicos passam a ser definidos e tratados como problemas médicos, habitualmente em termos de doença e distúrbios [illness and disorders]" 10 A capacidade de definição (logo, de produção) da realidade é a questão fundamental: "a chave da medicalização é a definição. Isto é, um problema é definido em termos médicos, descrito usando linguagem médica, entendido através da adoção de um enquadramento [framework] médico, ou "tratado" com uma intervenção médica".11

8 GOWAN, Teresa. Hobos, Hustlers and Backsliders: Homeless in San Francisco. Minneapolis: University of Minnesota Press, 2010. HOPPER, Kim. Reckoning with Homelessness. Ithaca: Cornell University Press, 2003. LOVELl, Anne M. "Classification and its Risks: How Psychiatric Status Contributes to Homelessness Policy". In: New England Journal of Public Policy, vol. 8, n. 1, 1992, pp. 247-263. LYON-CALLo, Vincent. Inequality, Poverty and Neoliberal Governance. Toronto: University of Toronto Press, 2008 [ed. orig.: 2004]. MATHIEU, Arline. "The Medicalization of Homelessness and the Theater of Repression". In: Medical Anthropology Quarterly, vol. 7, n. 2, 1993, pp. 170-184. WASSERMAN, Jason Adam; CLAIR, Jeffrey Michael. At Fome on the Street: People, Poverty \& a Hidden CuIture of Homelessness. Boulder e London: Lynne Rienner Publishers, 2010.

9 CONRAD, Peter. "Medicalization and Social Control". In: Annual Review of Sociology, n. 18, 1992, pp. 209-232. CONRAD, Peter. The Medicalization of Society: On the Transformation of Human Conditions into Treatable Disorders. Baltimore: The John Hopkins University Press, 2007. CONRAD, Peter; SCHNEIDER, Joseph w. Deviance and Medicalization: From Badness to Sickness. Expanded Edition, with a new afterword by the authors. Philadelphia: Temple University Press, 1992 [ed. orig. 1980].

10 CONRAD, Peter. The Medicalization of Society: On the Transformation of Fuman Conditions into Treatable Disorders. Baltimore: The John Hoplkins University Press, 2007 , p. 4 . Todas as citações em língua original que não o português foram por mim traduzidas. 11 Ibid., p. 5.

93 | Pensando-Revista de Filosofia Vol. 10, № 19, 2019

ISSN $2178-843 x$ 
A presença de profissionais médicos contribui para a medicalização de um fenómeno, nomeadamente, ao permitir o acesso a certos procedimentos médicos (diagnósticos, tratamentos, entrada e permanência em instituições médicas). Contudo, "a medicalização não é, nem nunca foi, "imperialismo médico" ". 12 A extensão de uma racionalidade médica a um campo de vida é um processo coletivo que, necessariamente, envolve múltiplos atores com posições reticulares variadas.

Na intervenção sobre a vida na rua, as ligações entre instituições assistencialistas (públicas e privadas) e do dispositivo médico mental são frequentes, por vezes, oficializadas através de protocolos interinstitucionais. Em diversos tipos de interação, quer em situações em que a forma da intervenção sobre a vida na rua é decidida quer em momentos em que esta é concretizada, os profissionais do dispositivo médico mental têm um papel relevante, estimulando a mobilização de grelhas de leitura e formas de ação médicas mentais. Ora, não é espantoso que as interações em que estes atores estão presentes tenham a forma médica que lhes é própria.

Porém, crescentemente, mesmo nos espaços e momentos em que não estão presentes profissionais do dispositivo médico mental, a gestalt sob a qual a vida na rua é percebida e as práticas pelas quais ela é intervencionada têm a sua sócio-génese no modelo médico mental. Assim, para diversos profissionais nãomédicos da intervenção (tal como para sujeitos domiciliados não diretamente ligados à intervenção), a vida na rua é entendida como o resultado inevitável da anormalidade biomédica de cada indivíduo sem-abrigo. Esta menoridade íntima de cada indivíduo sem-abrigo expressa-se pela sua doença e/ou deficiência mental, 13 que torna cada um deles incapaz de se conduzir de uma forma correta, o que leva a que perturbem os não-sem-abrigo que com eles se cruzam, tal como leva a que sejam incapazes de cuidar de si próprios sem apoio especializado de profissionais da intervenção assistencialista e médica mental.

Em função disto, a intervenção sobre a vida na rua fragmenta-se numa multiplicidade de intervenções sobre cada indivíduo que nela vive, intervenções estas que devem corresponder a formas de tratamento médico (e.g., frequência de consultas de psicologia e psiquiatria, toma de medicação psiquiátrica, internamento em espaços psiquiátricos). Contudo, mesmo as relações estabelecidas entre sem-abrigo e profissionais não-médicos (e.g., assistentes sociais) passam a assumir uma forma interacional derivada da relação terapêutica médicopaciente e assente em quadros conceptuais médicos mentais. Com ou sem tratamento médico efetivo, o objetivo teórico dos procedimentos da intervenção é o mesmo: normalizar a anormalidade de quem vive na rua de modo a que cada indivíduo sem-abrigo seja capaz de regressar à sociedade domiciliada. 14

12 Ibid., p. 149.

13 Mas também pela sua toxicodependência e/ou pelo seu alcoolismo na medida em que, nas últimas décadas, estas questões foram em si mesmas ressignificadas num campo medicalizado.

14 GOWAN, Teresa. Hobos, Hustlers and Backsliders; Homeless in San Francisco. Minneapolis: University of Minnesota Press, 2010. HOPPER, Kim. Reckoning with Homelessness. Ithaca: Cornell University Press, 2003. LOVELL, Anne M.

94 | Pensando-Revista de Filosofia Vol. 10, № 19, 2019 ISSN $2178-843 x$ 
Um dos principais efeitos da medicalização é o obscurecimento estrutural dos fenómenos sociopolíticos sobre os quais incide. Nesta medida, o processo, inevitavelmente, produz efeitos de proteção, legitimação e reprodução estrutural dado que o foco da compreensão e intervenção medicalizada é a resolução de problemas do indivíduo no indivíduo. Ao nível dos discursos e representações, mas também de diversos procedimentos de intervenção - que, não deixando de ser relacionais, visam individualizar e individuar -, os problemas, necessariamente, são feitos transitar do domínio da interação - imediata ou indireta e mediada (i.e., estrutural) - para o da biologia individual. 15

Esta invisibilização das propriedades estruturais do modelo societal moderno ocidental gerada pela medicalização da vida na rua sustenta a tónica colocada pela intervenção na normalização de cada indivíduo sem-abrigo. A medicalização de um campo de vida produz (e visa produzir) sempre efeitos de normalização num duplo (e articulado) sentido. Desde logo, este processo implica um exercício pelo qual se procura adaptar os sujeitos intervencionados à norma biomédica, científica (ou com pretensões de alcançar este estatuto) e estatisticamente verificável. Mas, em simultâneo, a intervenção de génese médica - e, sobretudo, médica mental - visa também adaptar os sujeitos à normatividade jurídica e cultural (não escrita, mas transmitida, incorporada e lentamente modificada na sucessão das gerações) vigente num dado espaço-tempo.16

“Classification and its Risks: How Psychiatric Status Contributes to Homelessness Policy". In: New England Journal of Public Policy, vol. 8, n. 1, 1992, pp. 247-263. LYON-CALLO, Vincent. Inequality, Poverty and Neoliberal Governance. Toronto: University of Toronto Press, 2008 [ed. orig.: 2004]. MATHIEU, Arline. "The Medicalization of Homelessness and the Theater of Repression". In: Medical Anthropology Quarterly, vol. 7, n. 2, 1993, pp. 170-184. WASSERMAN, Jason Adam; CLAIR, Jeffrey Michael. At Home on the Street: People, Poverty \& a Hidden CuIture of Homelessness. Boulder e London: Lynne Rienner Publishers, 2010.

15 CONRAD, Peter. "Medicalization and Social Control". In: Annual Review of Sociology, n. 18, 1992, pp. 209-232. CONRAD, Peter. The Medicalization of Society: On the Transformation of Human Conditions into Treatable Disorders. Baltimore: The John Hopkins University Press, 2007. CONRAd, Peter; SChNEIDER, Joseph W. Deviance and Medicalization: From Badness to Sickness. Expanded Edition, with a new afterword by the authors. Philadelphia: Temple University Press, 1992 [ed. orig. 19801. NYE, Robert A. crThe Evolution of the Concept of Medicalization in the Late Twentieth Century". In: Journal of History of the Behavioral Sciences, vol. 39, n. 2 , 2003, pp. 115-129. SZASZ, Thomas. “The Myth of Mental Illness". In: Idem. Ideology and Insanity: Essays on the Psychiatric Dehumanization of Man. Syracuse: Syracuse University Press, 1991 [ed. orig.: 1960], pp. 12-24. Uma exposição deste argumento para o caso específico da assistência aos sujeitos pobres encontra-se em SCHRAM, Sanford F. After Welfare: The culture of postindustrial social policy. New York: New York University Press, 2000, pp. 59-88. Para o caso concreto da vida na rua cf. BL.AU, Joel. The Visible Poor: Homelessness in the United States. New York e Oxford: Oxford University Press, 1992. GOWAN, Teresa. Hobos, Hustlers and Backsliders: Homeless in San Francisco. Minneapolis: University of Minnesota Press, 2010. HOPPER, Kim. Reckoning with Homelessness. Ithaca: Cornell University Press, 2003. LYON-CALLo, Vincent. Inequality, Poverty and Neoliberal Governance. Toronto: University of Toronto Press, 2008 [ed. orig.: 2004]. MATHIEU, Arline. “The Medicalization of Homelessness and the Theater of Repression". In: Medical Anthropology Quarterly, vol. 7, n. 2, 1993, pp. 170-184. WASSERMAN, Jason Adam; CLAIR, Jeffrey Michael. At Home on the Street: People, Poverty d a fidden Culture of Homelessness. Boulder $\mathrm{e}$ London: Lynne Rienner Publishers, 2010.

16 FOUCAULT, Michel. "About the Concept of the "Dangerous Individual" in 19thCentury Legal Psychiatry". In: International Journal of Law and Psychiatry, n. 1, 1978, pp. 1-18. FOUCAULT, Michel. Les anormaux; Cours au Collège de France, 19741975. Paris: EHESS, Gallimard, Seuil, 1999. FOUCAULT, Michel, Histoire de la folie à 
Esta face de Janus da normalização levada a cabo pela medicalização é indissociável da perceção social do estado patológico. Como Conrad e Schneider precisam, "dado que as doenças são julgamentos sociais, elas são julgamentos negativos"17, i.e., são estados indesejáveis, a evitar e/ou retificar (curar) se possível. Em certos casos, nos quais se incluem muitíssimas das situações com as quais lida a medicina mental, esta ligação entre a negatividade da doença e a normalização do doente leva a que o estado patológico seja transferido para a ontologia do próprio sujeito rotulado como doente. Neste sentido, a psiquiatrização produz uma indeterminação fundamental entre estado-doença e sujeito-doente, fazendo com que a negatividade imputada ao primeiro transite para o segundo. Esta deslocação da negatividade do estado para a ontologia condiciona de modo fundamental as formas e possibilidades de vida dos sujeitos patologizados, podendo mesmo diminuí-las de maneira significativa, sobretudo, naqueles casos em que a avaliação normativa da doença-doente é particularmente negativa.18

- enorme peso da cosmologia e das práticas médicas mentais, sobretudo, neuro-psiquiátricas, é observável em diversos discursos e procedimentos da intervenção sobre a vida na rua. Para a maioria dos profissionais da intervenção, o malestar sentido por quem vive na rua tende a ser deslocado para o seu íntimo problemático, deixando de ser uma questão de desqualificação política, de privação material ou de violência estrutural para se converter numa sucessão pontilhista de depressões clínicas, psicoses, debilidades mentais, adições bioquímicas a drogas ilegais e álcool, entre outras patologias psiquiátricas. Portanto, as representações dominantes dos profissionais da intervenção sobre o que os sem-abrigo são e sobre que problemas têm (leia-se: que problemas são) assentam na sua anormalidade biomédica, nomeadamente, neuro-psiquiátrica. Desde logo, esta sua inferioridade íntima é de per se entendida como causa explicativa para o facto dos sujeitos viverem na rua. É no campo de uma forma de vida caracterizada de modo incontornável por uma essência onto-neuro-psiquiátrica menor

l'âge classique. Paris: Gallimard, 2010a [ed. orig.: 1972]. FoucAult, Michel. Maladie mentale et psychologie. Paris: PUF, 2011 [ed. orig.: 1954], pp. 71-101. FOUCAULT, Michel. Surveiller et punir: Naissance de la prison. Paris: Gallimad, 2012 a [ed. orig.: 1975].

17 CONRAD, Peter; SCHNEIDER, Joseph W. Deviance and Medicalization: From Badness to Sickness. Expanded Edition, with a new afterword by the authors. Philadelphia: Temple University Press, 1992 [ed. orig. 1980], p. 31.

18 CONRAD, Peter; SCHNEIDER, Joseph W. Deviance and Medicalization: From Badness to Sickness. Expanded Edition, with a new afterword by the authors. Philadelphia: Temple University Press, 1992 [ed. orig. 1980]. FOUCAULT, Michel. "About the Concept of the "Dangerous Individual" in 19th-Century Legal Psychiatry". In: International Journal of Law and Psychiatry, n. 1, 1978, pp. 1-18. FOUCAULT, Michel. Les anormaux: Cours au Collège de France, 1974-1975. Paris: EHESS, Gallimard, Seuil, 1999. FOUCAULT, Michel, Histoire de la folie à l'âge classique. Paris: Gallimard, $2010 a$ [ed. orig.: 1972]. FOUCAULT, Michel. Maladie mentale et psychologie. Paris: PUF, 2011 [ed. orig.: 1954], pp. 71-101. FOUCAULT, Michel. Surveiller et punir: Naissance de la prison. Paris: Gallimad, 2012 a [ed. orig.: 1975]. MATHIEU, Arline. "The Medicalization of Homelessness and the Theater of Repression". In: Medical Anthropology Quarterly, vol. 7, n. 2, 1993, pp. 170-184. SZASZ, Thomas. “The Myth of Mental Illness". In: Idem. Ideology and Insanity: Essays on the Psychiatric Dehumanization of Man. Syracuse: Syracuse University Press, 1991 [ed. orig.: 1960], pp. 12-24.

96 | Pensando - Revista de Filosofia Vol. 10, № 19, 2019

ISSN $2178-843 x$ 
que, para profissionais assistencialistas e da área da medicina mental - bem como, crescentemente, para jornalistas, representantes políticos formais, académicos, etc. - se encontra a causalidade de cada vida individual passada na rua, o leitmotif de toda a intervenção sobre essa individualidade patológica e, eventualmente, alguma possibilidade de transformação de si, percebida como resposta possível para o problema que o sujeito é.

\section{O grotesco como característica da medicalização}

Ao ter a capacidade de definir uma esfera da existência humana como um problema médico e de agir sobre ela mobilizando procedimentos cuja origem se encontra no modelo médico, a medicalização da vida na rua implica o desenvolvimento de certas formas de condicionar aquilo que os sujeitos - domiciliados e sem-abrigo - percebem, dizem e fazem. Nesta medida, a medicalização da vida na rua é, simultaneamente, um fenómeno de saber e de poder. Como Foucault defendeu, saber e poder não são fenómenos independentes mas, pelo contrário, são sempre duas facetas de um mesmo fenómeno.19 A profunda imbricação de ambos leva a que eles surjam sempre na forma inextricável de saber-poder, indicando que todos os atos de poder têm efeitos de saber, geram saber, influenciam a distribuição dos enunciados e sujeitos ao longo de um campo de saber, e, de forma recíproca, todos os atos de saber têm consequências de poder, geram poder, influenciam a distribuição dos enunciados e sujeitos ao longo de um campo de poder.

Uma das propriedades basilares dos exercícios de poder pelos quais a vida na rua é medicalizada é o seu caráter grotesco. o termo grotesco deve ser entendido no sentido preciso que Foucault lhe atribui, tratando-se de algo, de alguém, de algum enunciado, de alguma forma social, que, por estatuto, pode produzir efeitos de realidade que a sua "qualidade intrínseca" torna injustificados.20 Nas palavras de Foucault,

quando digo ugrotescon, quero empregar [o termo] num sentido se não absolutamente estrito, pelo menos um pouco mais rigoroso ou sério. Designo "grotesco" o facto, para um discurso ou para um indivíduo, de deter por estatuto efeitos de poder de que a sua qualidade intrínseca os deveria privar. 0 grotesco, ou, se desejarem, o ubuescon, não é simplesmente uma categoria de injúrias, não é um epíteto injurioso, e não o desejo empregar nesse

19 FOUCAULT, Michel. “Truth and Power". In: GORDON, Colin (org.); FOUCAULT, Michel. Power/Knowledge: Selected Interviews and Other Writings, 1972-1977. New York: Pantheon, 1980 [ed. orig.: 1977], pp. 109-133. FOUCAULT, Michel. Fistória da sexualidade - If A vontade de saber. Lisboa: Relógio D’Água, 1994 [ed. orig.: 1976]. FOUCAULT, Michel. "É preciso defender a sociedaden: Curso no Collège de France (1975-1976). Lisboa: Livros do Brasil, 2006 [ed. orig.: 1997]. FOUCAULT, Michel. Nascimento da biopolítica. Lisboa: Edições 70, 2010 b [ed. orig.: 2004]. FOUCAULT, Michel Surveiller et punir: Naissance de la prison. Paris: Gallimad, 2012 a [ed. orig.: 1975]. FOUCAULT, Michel Du gouvernement des vivants: Cours au Collège de France, 1979-1980. Paris: EHESS, Gallimard, Seuil, $2012 \mathrm{~b}$.

20 FOUCAULT, Michel. Les anormaux: Cours au Collège de France, 1974-1975. Paris: EHESS, Gallimard, Seuil, 1999, pp. 12 et seg.

97 | Pensando-Revista de Filosofia Vol. 10, № 19, 2019

ISSN $2178-843 X$ 
sentido. Creio que existe uma categoria precisa; deveríamos, em todo o caso, definir uma categoria precisa de análise histórico-política, que seria a categoria do grotesco ou o ubuesco. 0 terror ubuesco, a soberania grotesca ou, em termos mais austeros, a maximização dos efeitos de poder a partir da desqualificação de quem ou daquilo que [ce celuy] os produz: isto, creio, não é um acidente na história do poder, não é uma falha da mecânica. Parece-me que é uma das rodas da engrenagem que fazem parte inerente dos mecanismos de poder.21

O grotesco, portanto, é uma categoria que remete para uma situação na qual o poder é exercido a partir da desqualificação fundamental dos sujeitos (sejam eles indivíduos ou instituiçốes) que o exercem, bem como dos enunciados (saber) através dos quais estes produzem efeitos de realidade (poder).

De modo imediato, as avaliações sobre a doença e/ou deficiência mental de sem-abrigo realizadas por profissionais assistencialistas sem formação na área da medicina mental (e.g., assistentes sociais), que contribuem significativamente para a produção de diagnósticos psiquiátricos de sem-abrigo, são compreensíveis como expressões do grotesco. Do mesmo modo, são manifestações do grotesco os frequentes episódios em que uma grelha conceptual da medicina mental, supostamente científica, é mobilizada de forma não rigorosa, sem a precisão que a psicologia ou a psiquiatria reivindicam quando se apresentam publicamente como ciência, rotulando quem vive na rua como doente e/ou deficiente mental após escassos minutos de interação ou mesmo, por vezes, sem conhecer um sujeito face a face mas, meramente, diagnosticando-o a partir de breves relatos de terceiros.

Porém, o caráter grotesco da medicalização da vida na rua é mais abrangente do que isto. Este processo é grotesco de base pois opera através de rotulagens biomédicas (ontológicas) da anormalidade de sem-abrigo que são realizadas através de avaliações de condutas de quem vive na rua que, muitíssimas vezes, não levam em conta nem as propriedades estruturais da própria vida na rua nem a forma específica como cada sujeito experiencia a vida na rua. Portanto, a medicalização da vida na rua tem uma dimensão inerentemente grotesca pois este processo é duplamente desancorado da praxis da própria vida na rua. Por um lado, é estruturalmente desancorado, não enquadrando a vida na rua no modelo societal em que existe, não a relacionando com a forma como este está organizado, com as características dos mercados de trabalho e habitacional, com o modo como o Estado e as instituições não-estatais se relacionam com os sujeitos e, sobretudo, não procurando compreender as propriedades interacionais próprias da vida na rua - a desqualificação, a violência, o medo, a privação ou as condutas pelas quais os semabrigo procuram enfrentá-las. Por outro lado, a medicalização é desancorada da praxis da experiência biográfica que cada semabrigo faz da vida na rua, não procurando entender a forma como cada indivíduo se insere no universo da rua, como se relaciona 
com outros sujeitos (sem-abrigo e domiciliados) e instituições ou como tenta fazer face à insegurança física, social e ontológica que sente. Prescindindo de ancoragem na praxis, a medicalização processa-se por intuições mais ou menos (des)informadas sobre a esfera da existência humana intervencionada, substituindo o conhecimento aprofundado pela estandardização dos rótulos e procedimentos psiquiátricos e psicológicos, que são concretizados por sujeitos domiciliados que, com um imponderável bom ou mau senso, detêm o arbítrio de decidir se e como medicalizar cada pormenor (conduta, fala, sujeito) da vida na rua.

Sendo um processo caracterizado por exercícios de poder grotescos, a medicalização da vida na rua leva a que os enunciados emitidos pelos sujeitos que patologizam as condutas - e logo, a ontologia - dos sem-abrigo surjam como um discurso de tipo idiossincrático. Segundo Foucault, o exercício de um poder grotesco produz um discurso de verdade que, em simultâneo, pode matar e faz rir.22 Os enunciados do grotesco são um discurso de verdade pois determinam o que pode ou não ser dito e como pode ou não ser dito, estabelecendo o que é ou não aceite, logo, delimitam as possibilidades de existência, circunscrevem as possibilidades de realidade.23 Mas, em simultâneo, um exercício de poder grotesco apresenta-se como um discurso que faz rir e como um discurso que pode matar. "Que faz rirn, dado que a desqualificação do enunciado e do sujeito que enuncia anda a par da possibilidade de exercício desta forma de poder, é sua conditio sine qua non. "Que pode matar", pois trata-se de um discurso que tem o privilégio institucional de decidir, de conceder ou de eliminar as possibilidades de vida dos sujeitos sobre os quais enuncia.

Portanto, a dimensão grotesca dos exercícios de poder medicalizado e medicalizante na vida na rua produz discursos de verdade que podem matar, que podem reduzir as possibilidades de vida de quem vive na rua, que podem matar fisicamente, no longo prazo (ao negar um teto, ao negar uma refeição) e, sobretudo, que podem matar politicamente. Mas, estabelecendo a verdade e podendo matar, estes exercícios de poder não podem deixar de provocar um riso trágico. No preciso momento em que o poder medicalizado e medicalizante se manifesta na vida na rua, ele desqualifica-se a si mesmo. Em grande medida, desqualificase pois a patologização ubíqua das condutas e dos discursos dos sem-abrigo é empiricamente desancorada quer graças à invisibilização de propriedades estruturais elementares da vida

22 Ibid., pp. 7 et seq.

23 FOUCAULT, Michel. “Truth and Power". In: GORDON, Colin (org.); FOUCAULT, Michel. Power/Knowledge: Selected Interviews and Other Writings, 1972-1977. New York: Pantheon, 1980 [ed. orig.: 1977], pp. 109-133. FOUCAULT, Michel. Fistória da sexualidade - If A vontade de saber. Lisboa: Relógio D'Água, 1994 [ed. orig.: 1976]. FOUCAULT, Michel. A ordem do discurso: Aula inaugural no Collège de France, pronunciada em 2 de dezembro de 1970. Lisboa: Relógio D’Água, 2005 [ed. orig.: 19711 . FOUCAULT, Michel. "É preciso defender a sociedaden: Curso no Collège de France (1975-1976). Lisboa: Livros do Brasil, 2006 [ed. orig.: 1997]. FOUCAULT, Michel. Nascimento da biopolítica. Lisboa: Edições 70, 2010b [ed. orig.: 2004]. FOUCAULT, Michel Surveiller et punir: Naissance de la prison. Paris: Gallimad, 2012 a [ed. orig.: 1975]. FOUCAULT, Michel Du gouvernement des vivants: Cours au Collège de France, 1979-1980. Paris: EHESS, Gallimard, Seuil, 2012b. 
na rua, quer devido à ausência de contextualização biográfica das condutas dos sem-abrigo patologizados.24

Sendo um discurso de verdade, a patologização biomédica individual dos sem-abrigo adquire um privilégio epistémico de definição conceptual e praxiológica. Esta dominação epistémica leva a que tudo aquilo que os sem-abrigo fazem e dizem - bem como, muitas vezes, o que não fazem e não dizem - seja passível de ser exogenamente interpretado como sintoma de um problema neuro-psiquiátrico ou psicológico. Esta omnipresente possibilidade de leitura upsill da vida na rua é quotidianamente observável nos discursos e atos de diversos profissionais de instituições responsáveis pela intervenção neste fenómeno. Para estes sujeitos, poucas condutas de sem-abrigo existem que não sejam passíveis de indicar a sua doença e/ou deficiência mental.

De seguida, discuto alguns casos de patologização de condutas de sem-abrigo que expressam de modo particularmente claro o grotesco da medicalização da vida na rua. Em todos eles estão em causa definições de realidade que pretendem alcançar a exclusividade, dando origem a procedimentos de intervenção que condicionam as vidas de quem vive na rua. Apesar de cada caso se reportar a sujeitos e momentos específicos, nenhum deles se esgota nesta especificidade, apontando para lógicas gerais da circulação da verdade e do exercício do poder na intervenção sobre a vida na rua.

\section{Momentos do grotesco}

O episódio seguinte ocorreu na primavera de 2014, numa reunião entre profissionais de instituições assistencialistas e do dispositivo psiquiátrico. Um assistente social descrevia aos restantes presentes o comportamento de um sem-abrigo que, segundo ele, interagia pouco com outros sujeitos, quase não falando com ninguém e não percebendo o que lhe diziam. Para mais, ria-se muito, com um riso caracterizado pelo narrador como débil.

Enquanto descreve o sem-abrigo em questão, o assistente social imita de modo depreciativo e hiperbólico a expressão facial do primeiro quando este se ri, enfatizando o seu caráter ridículo. Nas palavras deste assistente social, "se lhe disser cvamos comer?', ele diz 'sim, sim'. Se lhe disser 'não vamos comer?', ele diz 'não, não."'. Tudo é relatado procurando provocar o riso dos restantes presentes. A face propositadamente desfigurada e a voz

24 Estas não são as únicas características discursivas do grotesco. Apesar de serem as únicas explicitadas por Foucault, é defensável que, entre outras coisas, tal é devido ao posicionamento metodológico do autor, que assentava de modo privilegiado (mas, em definitivo, não exclusivo) na pesquisa de arquivo e na reflexão histórico-filosófica ensaística. Estudar a praxis a partir do contacto direto com o presente que é permitido pela observação direta das práticas dos sujeitos revela outras facetas do grotesco, complementares da definição da verdade, da possibilidade de matar e do facto de fazer rir. Olhar para as práticas grotescas no momento em que se concretizam, ouvindo os enunciados que as suportam sem a distância intelectual e emocional possibilitadas pelo arquivo ou pela reflexão tida no gabinete de trabalho, leva a que, por vezes, o riso provocado pelo grotesco seja substituído no imediato pela ira e pelo desespero. Portanto, ver a redução de possibilidades de vida de certos sujeitos a ser feita à nossa frente faz do grotesco também um discurso que faz chorar, que enjoa, que causa mal-estar físico e emocional, e que enfurece e indigna perante a violência que se observa. 
distorcida usadas pelo assistente social para descrever a conduta do sem-abrigo são representações reflexivamente imperfeitas da incapacidade neuro-psiquiátrica do segundo, mobilizadas pelo seu valor humorístico. Na interação da reunião, o desajustamento entre a realidade que se procura descrever, risível na sua debilidade, e a performance conscientemente débil pela qual a primeira é apresentada em público pelo assistente social não implicam uma desqualificação da descrição pela sua inexatidão. Antes, o ridículo da performance sustenta e magnifica o ridículo do sujeito descrito, retificando qualquer separação entre eles que a falta de rigor da primeira pudesse ter introduzido na interação. Para o efeito da intervenção sobre a vida na rua que estava a ser coordenada naquela reunião, através da apresentação depreciativa e humorística, a realidade da menoridade biomédica é demonstrada em toda a sua perfeita imperfeição. A exatidão da narrativa descritiva da empiria decorre precisamente da hipérbole humorística, logo, decorre da sua inexatidão, levando a que, paradoxalmente, a falta de rigor da descrição forneça em si mesma rigor à análise da empiria levada a cabo pelo assistente social.

Por este motivo, a análise e discussão reflexivas dos presentes sobre um sujeito sem-abrigo que muitos deles desconhecem pode prescindir da observação in situ da sua conduta e assentar em exclusivo na descrição de outrem. Toda a performance descritiva demora menos de cinco minutos. Apenas com base neste relato, um psiquiatra presente na reunião considera não necessitar de informação adicional para definir a insuficiência mental do sem-abrigo em questão. Interrompendo o relato humorístico do assistente social - que poderia prolongar-se enquanto permanente repetição de si mesma na ausência desta intervenção -, o psiquiatra exclama: "Então, tem uma debilidade grave! Nem preciso olhar para o homem". Sem olhar para o sujeito sem-abrigo descrito, sem sequer saber quem ele é, e sem possuir qualquer outra informação sobre ele, o psiquiatra diagnostica-o.

o grupo decide levar o sem-abrigo em questão ao hospital psiquiátrico onde trabalha o psiquiatra para que este 0 consulte. Porém, o diagnóstico já está de facto feito. A deslocação do semabrigo a uma consulta médica visa menos produzir um diagnóstico do que validá-1o. A confiança com que o psiquiatra apresenta a classificação de debilidade mental grave mostra isto mesmo - sobretudo, quando é enquadrada no restante trabalho de observação de reuniôes interinstitucionais semelhantes nas quais - mesmo grau de certeza se repetia frequentemente. Poucas situações demonstram de forma mais clara o argumento de Laing de que os diagnósticos de doença mental - ou, no caso, de debilidade mental - surgem a priori da interação face a face entre médico e paciente, levando a que, quando esta finalmente ocorre, - primeiro apenas procure identificar (produzir) os sinais e sintomas que suportam o diagnóstico apriorístico, que não podem deixar de estar presentes.25

Do mesmo modo, poucas ocasiões relevam de forma mais nítida o caráter grotesco da medicalização da vida na rua. $A$

25 LAING, Ronald David. The Divided Self An Existential Study in Sanity and Madness. London: Penguin, 2010 [ed. orig.: 1960], p. 28.

101 | Pensando-Revista de Filosofia Vol. 10, № 19, 2019

ISSN $2178-843 x$ 
enunciação hiperbólica com intenções humorísticas que é mobilizada para descrever a menoridade neuro-ontológica do sujeito sem-abrigo é uma expressão inegável da desqualificação do sujeito que enuncia. Ele propositadamente desqualifica-se a si mesmo para transmitir a informação que pretende partilhar, reduzindo-se à imbecilidade performatizada no mesmo movimento pelo qual exerce um ato de poder com consequências fundamentais sobre a vida do sujeito sem-abrigo que descreve. Não se trata somente de 0 assistente social ter a prerrogativa de exercer poder deste modo, de a sua ação ter efeitos de realidade consequentes apesar da sua desqualificação pela forma da enunciação. De modo bastante mais fundamental, este exercício de poder é indissociável da sua desqualificação. É certo que seria plausível que o mesmo sujeito exercesse um condicionamento sobre a vida do sem-abrigo descrito sem necessitar de se desqualificar. Porém, desqualificando-se, este ato torna-se condition sine qua non da própria engrenagem do poder - que passa a assentar de base na desqualificação de quem o exerce.

A posição dos restantes envolvidos na reunião revela igualmente o caráter grotesco da medicalização da vida na rua. Inegavelmente, os enunciados que circulam conjugam-se para produzir um discurso de verdade sobre a vida daquele sem-abrigo e, de modo mais geral, sobre a vida na rua. A cosmologia médica mental e os procedimentos de intervenção por ela guiados são tomados como óbvios, levando a que, aos olhos dos profissionais encarregues da intervenção sobre este fenómeno, sejam automaticamente validados. A vida na rua é um problema de patologia mental individual, portanto, qualquer descrição que dela se faça não pode deixar de verificar a presença de tais patologias. Os limites de possibilidade da enunciação sobre a vida na rua são, assim, severamente estabelecidos, relegando todas as outras leituras plausíveis deste fenómeno para o campo da falsidade, do erro ou mesmo do impensável. Mas este discurso de verdade não pode deixar de ter como um dos seus efeitos potenciais - mais até, inevitáveis - a redução de possibilidades de vida de quem vive na rua. Ao ser inserido como sujeito e como objeto num tal campo discursivo, um sujeito sem-abrigo vê as suas possibilidades de vida tornarem-se dependentes das opinióes, decisões e ações dos atores do dispositivo assistencialistapsiquiátrico. No caso discutido, o sujeito é de forma muitíssimo direta construído como incapaz de se autogovernar - "tem uma debilidade grave!' -, logo, a forma exógena do seu governo ficará precisamente ao cuidado dos atores que o definem como incapaz. As condições de possibilidade da sua vida ficarão entregues à vontade de outrem, reduzindo-se o campo da ação autodeterminada do sujeito. Por último, assentando na desqualificação de quem o enuncia, este discurso de verdade que reduz possibilidades de vida não pode deixar de fazer rir. Ele é duplamente risível. A um nível autorreflexivo, o sujeito que dá origem a este exercício de poder com a sua narrativa descritiva apela em permanência ao caráter cómico daquilo que descreve e da forma como o descreve. Mas, visto de fora, este modo de exercer poder reveste-se de uma dimensão ridícula da qual nunca se poderá libertar. 0 riso provocado ao observador é, necessariamente, um riso trágico, mas ocorre apesar disto.

102 | Pensando - Revista de Filosofia Vol. 10, № 19, 2019 ISSN $2178-843 X$ 
A desancoragem empírica deste exercício de poder é inextricável das suas características grotescas - em particular, da sua capacidade para formatar a verdade sobre a vida daquele sujeito sem-abrigo e sobre a vida na rua. Aliás, o grotesco emerge aqui, precisamente, a partir da ausência de ancoragem empírica do exercício do poder; ele surge porque quem exerce poder tem a prerrogativa de definir a inferioridade neuro-psiquiátrica daquele sem-abrigo como verdade inevitável que, assim, prescinde de verificação empírica, dispensa uma análise rigorosa, pormenorizada e enquadrada da vida daquele sujeito na rua. De base, ele é ontologicamente menor e esta sua menoridade tem uma forma biomédica. Logo, nos exercícios de poder que se desenvolvem sobre a sua vida, não se trata procurar o seu estatuto onto-psiquiátrico, não é questão de avaliar a sua relação com normalidade biomédica. Antes, estando esta a priori definida, os exercícios de poder buscam tão somente validar a menoridade do sujeito, tornando a praxis da sua vida num elemento razoavelmente irrelevante para este efeito. Minuciosamente escrutinada ou descrita de modo célere, cómico e depreciativo, a vida concreta daquele sujeito não pode deixar de verificar a definição apriorística da sua anormalidade, tornando o conhecimento empírico desnecessário.

Uma vez que é este o contexto de verdade e de poder em que a intervenção sobre a vida na rua se desenvolve, há uma imensidão de condutas e características de sem-abrigo grotescamente percebidos-construídos por profissionais da intervenção como indicadores da sua doença e/ou deficiência mental. Um dos domínios da intervenção em que o caráter grotesco da medicalização da vida na rua se revela de modo mais claro encontra-se nos procedimentos de patologização da alimentação dos sem-abrigo. A este nível, é visível todo um conjunto de incongruências no modo dominante de entender e intervir neste fenómeno sociopolítico.

Ao discutirem a alimentação de quem vive na rua, diversos profissionais de instituições assistencialistas mesclam classificações de inferioridade neuro-psiquiátrica com juízos amoralizantes de sujeitos sem-abrigo. Para vários destes profissionais, quem vive na rua não deve nem precisa de gastar dinheiro em comida pois as instituições para que trabalham fornecem comida gratuitamente a quem dela necessita, devendo antes utilizar o seu dinheiro para pagar rendas habitacionais (não importando qual a forma da habitação) de modo a sair da rua em sentido literal.

Este argumento é incongruente com as repetidas lamentações destes mesmos profissionais a respeito da escassez de alimentos que têm para dar a quem vive na rua - escassez essa que observei em diversos momentos de distribuição alimentar nos quais a comida a distribuir não chegava para todos os sujeitos que a pediam. Do mesmo modo, é aqui totalmente ignorado o tipo de comida que é fornecido a quem vive na rua, que tem um valor nutricional potencialmente problemático (excesso de açúcares processados, de sal ou de fritos, bem como escassez de proteínas, vegetais ou fruta) e que expressa uma negação organolética 
segundo a qual o sabor dos alimentos ingeridos é irrelevante para quem não tem dinheiro para pagar o que come.26

Porém, o ponto em que observei mais claramente um processo de patologização da alimentação de quem vive na rua, com contornos inegavelmente grotescos, ocorreu numa reunião interinstitucional no inverno de 2014. Enquanto os profissionais presentes discutiam a referida desnecessidade de quem vive na rua gastar dinheiro em comida, um dos presentes referiu ter descoberto recentemente uma "adição" (termo deste ator) que desconhecia. Tratava-se da dependência de comida, cuja existência foi prontamente validada por um psicólogo presente. 0 primeiro profissional avançou como fonte de informação um programa de televisão (não relativo à vida na rua) que teria visto no qual era exposto o facto de existirem pessoas que comem sem ter necessidade nutricional de o fazer, i.e., sem precisarem da alimentação ingerida para garantir a sua sobrevivência ou o seu bem-estar fisiológico. Tais dependentes de comida comem apenas pelo prazer de se sentirem saciados após a ingestão de alimentos. Como exemplo chocante disto, este profissional afirmou que existem mesmo sujeitos que sentem que têm de comer todos os dias, à mesma hora, "cinco caramelos" - um alimento que, implicitamente, era considerado supérfluo. Os restantes presentes responderam a este relato com uma mescla de humor e de ponderação profissional - sem que a segunda fosse invalidada pelo primeiro -, afirmando coletivamente que talvez fosse melhor começarem a pensar em formas de tratar os sujeitos sem-abrigo que sofrem desta patologia mental.

Ora, desde logo, este processo de patologização da alimentação de quem vive na rua é um exercício de poder grotesco pois parte de uma desqualificação fundamental de quem emite estes enunciados. Explicitamente, a fonte de informação em que a existência de uma tal patologia se ancora é um programa de televisão e não um conhecimento técnico-científico consistente sobre a questão - esse conhecimento apenas superficialmente surge a posteriori pela validação en passant do psicólogo presente. Mas a desqualificação de que parte este exercício de poder é também observável na definição implícita que os presentes - que, convém precisar, não têm qualquer formação na área da nutrição - avançam sobre que tipos de alimentos são ou não aceitáveis e/ou necessários para a vida de quem vive na rua. Para lá da manutenção fisiológica, tudo é inútil. Poderá ser um direito de sujeitos domiciliados com rendimentos mais elevados, mas não entra no campo do direito alimentar e organolético de quem vive na rua. Mas esta desqualificação de quem exerce o poder é também observável no óbvio desajustamento empírico desta linha de raciocínio quando mobilizada para pensar a vida na rua. Mesmo que a dependência de comida fosse passível de aceitação pacífica como patologia mental - e é argumentável que ela é, pelo contrário, uma condição elementar da existência

26 TERROLLE, Daniel. “Du mirage de l'urgence sociale à la realité anthropologique du terrain: Un bilain de recherche sur les sans-abri sur plus d'une décennie". In: Les Cahiers de I'Actif, n. 344/345, 2005, pp. 21-37. TERrolne, Daniel; AMISTANI, Carole. "L'alimentation des sans-abri: Entre autonomie et dependence". In: Anthropology of Food, n. 6, 2008. Consultado 22 de março de 2019, disponível em <http:/ljournals.openedition.org/aof/4952>

104 | Pensando-Revista de Filosofia Vol. 10, № 19, 2019

ISSN 21 78-843X 
humana -, e mesmo que fosse pacífico aceitar que a alimentação motivada pelo prazer organolético ou pela satisfação de se sentir saciado é em si mesma patológica - e é argumentável que ela é, antes, parte da condição humana nesta fase de desenvolvimento sócio-histórico do modelo societal moderno ocidental, onde a gastronomia é elevada a arte de vida -, seria na vida na rua, com todas as suas limitações, que se encontrariam casos notórios desta doença mental? A reflexão consistente ancorada no conhecimento empírico da vida na rua não pode deixar de revelar os inúmeros obstáculos que são colocados à alimentação básica dos sem-abrigo. Só ignorando isto é plausível pensar que os problemas alimentares da vida na rua se encontram no excesso ou no consumo prazeroso e não na escassez, na privação, na fome ou na doença fisiológica por elas provocada.

Esta patologização da forma da alimentação de quem vive na rua é particularmente paradoxal dado que coexiste com uma patologização da (suposta) recusa da alimentação. Neste ponto, é de referir o caso de um sem-abrigo que vários profissionais assistencialistas classificavam como neuro-psiquiatricamente anormal, suportando esta rotulagem, entre outras coisas, no facto dele não se deslocar à instituição assistencialista que fornece alimentação gratuita (ao almoço e ao jantar) a quem dela necessite (mediante aprovação do Instituto da Segurança Social) na cidade onde foi realizado o trabalho empírico que dá origem a este texto. Ora, como era fácil perceber conversando com este sujeito, ele evitava de facto deslocar-se a esta instituição, mas não por desejar não comer. Antes, o que motivava a sua evitação - não só da instituição como da zona da cidade em que ela se localiza era o seu enorme receio de que outros sem-abrigo que aí se encontravam habitualmente o agredissem - receito esse que era perfeitamente fundamentado na sua experiência biográfica, tendo eu presenciado mais de uma ocasião em que ele foi ameaçado. Portanto, o problema não era psiquiátrico, mas geográfico. Este sujeito comia quando tinha dinheiro para o fazer ou quando conseguia obter comida sem ter de se deslocar àquela zona da cidade. Patologizar a sua relutância a dirigir-se a este espaço só é possível à custa de um desenquadramento estrutural da violência da vida na rua e de uma isomórfica falta de contextualização da experiência biográfica daquele sujeito concreto na vida na rua.

Um dos indicadores de doença mental mais nitidamente decorrentes de uma absoluta ausência de enquadramento estrutural da conduta na vida na rua é o ato de vasculhar em caixotes do lixo em busca de comida. Aos olhos de vários profissionais assistencialistas e do dispositivo psiquiátrico, o facto de um sem-abrigo remexer no lixo não tem qualquer ligação significativa com a sua privação material. Sem qualquer outra consideração adicional, vasculhar no lixo indica de per se uma patologia mental.

Em grande medida, tal deve-se à absoluta confiança na operação do circuito interinstitucional assistencialista, que leva a que vários dos seus profissionais considerem que - pelo menos, na cidade utilizada como base empírica para esta investigação ninguém tem fome por falta de comida mas apenas por uma incapacidade neuro-psiquiátrica que leve os sujeitos a não

105 | Pensando - Revista de Filosofia Vol. 10, № 19, 2019 ISSN $2178-843 x$ 
procurarem os locais de distribuição gratuita de alimentação. Esta linha de raciocínio ignora os diversos sujeitos sem-abrigo que, por uma variedade de razões, não contactam com os serviços assistencialistas, tal como, convenientemente, esquece a experiência de diversos destes profissionais que, nos momentos de distribuição alimentar, se deparam - como eu me deparei diversas vezes quando os acompanhei - com o esgotamento da comida para distribuir antes desta ter sido entregue a todos os sujeitos que a pedem. Do mesmo modo, esta confiança irreflexiva no funcionamento da distribuição alimentar assistencialista é incongruente com os recorrentes desabafos e reclamaçôes dos mesmos profissionais quando estes falam na arrasadora escassez de recursos do setor assistencialista.

Sendo tudo isto invisibilizado, dentro de uma cosmologia medicalizada, o ato de vasculhar em caixotes do lixo à procura de alimentos não pode deixar de ser interpretado como um sintoma de doença mental. Como um assistente social exclamou, falando sobre um sujeito sem-abrigo concreto, "isto [de vasculhar em caixotes do lixo para encontrar comida] já ultrapassa [todos os limites] (...) Deve ter uma perturbação das valentes". Perturbação essa que foi imediatamente validada por um psiquiatra presente sem que este tivesse informação adicional que enquadrasse 0 ato de remexer no lixo. Em função da evidência da perturbação psiquiátrica indicada pelo ato de vasculhar em caixotes do lixo em busca de comida, este sujeito sem-abrigo "precisa de trabalho [terapêutico/psiquiátrico]", como refere outro profissional assistencialista. Porém, para que um tal trabalho fosse possível, ele não poderia continuar a circular irrestritamente pela cidade. Antes, tinha de ser internado compulsivamente numa instituição psiquiátrica - e, para isto, como comentou o psiquiatra, "só temos de o apanhar", considerando que tal poderia ser mais difícil do que desejaria.

Nenhum dos presentes na reunião em que esta troca de palavras ocorreu mostrou discordar deste modus operandi da intervenção sobre a vida na rua. Para a maioria dos profissionais de instituições assistencialistas e psiquiátricas, o facto de alguém comer comida que tira de caixotes do lixo é inteiramente despolitizado, não sendo compreendido como um reflexo da escassez arrasadora de recursos materiais. Antes, sendo desenquadrado de qualquer contexto estrutural, este facto é inteiramente interpretado como um sintoma de uma patologia individual.

Porventura, o caso observado em que a medicalização da vida na rua mais claramente revela o seu caráter grotesco pela total ausência de enquadramento empírico ou de reflexividade de quem exerce poder ocorreu numa reunião interinstitucional no inverno de 2014 . Nesta, foi abordado o caso de um imigrante da Europa de Leste, internado num hospital psiquiátrico aquando do relato, que, segundo o psiquiatra que o descrevia, "não percebe nada do que se passa à volta dele". Conscientemente, o psiquiatra em questão reconhecia que 0 indivíduo tinha um domínio muitíssimo rudimentar da língua portuguesa e nenhum dos profissionais do hospital psiquiátrico falava a língua materna do sujeito. Não obstante, a perceção de que ele não compreendia o que estava em causa nas interações em que estava envolvido levou

106 | Pensando-Revista de Filosofia Vol. 10, № 19, 2019 ISSN $2178-843 x$ 
a que ele fosse diagnosticado como débil mental. A falta de uma linguagem comum não impedia que os profissionais do hospital considerassem que ele teria, provavelmente - pois as dificuldades linguísticas impediam uma avaliação que, mesmo nos termos do dispositivo psiquiátrico, fosse passível de ser considerada rigorosa -, um coeficiente de inteligência reduzido. Ao relatar este caso, reflexivamente, o psiquiatra reconhece que 0 sujeito diagnosticado não possui um domínio suficiente da língua portuguesa para que seja possível dialogar com ele, tal como implicitamente reconhece que não fala a sua língua materna. Não obstante, com uma enorme segurança profissional e ontológica, afirma que ele não percebe o que se passa à sua volta, declarando mesmo que tem a sensação de que ele não perceberá muito do que lhe é dito na sua língua materna - que desconhece em absoluto.

No momento em que isto é relatado na reunião, muitos dos presentes riem-se, considerando que este sujeito deveria ter como prioridade aprender a língua portuguesa - ficando nítida, entre outras coisas, a opinião geral segundo a qual os imigrantes têm de se adaptar ao Estado-nação que os acolhe, devendo os seus direitos depender desta adaptação. No registo depreciativo e, a espaços, pretensamente humorístico em que o diálogo decorre, um dos profissionais assistencialistas presentes chega a afirmar que, sem falar português, este sujeito nem sequer conseguirá envolver-se romanticamente com uma mulher.

Independentemente disto, o ponto essencial é o de que o modelo de intervenção assistencialista-psiquiátrico dominante tem a prerrogativa de tornar irrelevante a incomensurabilidade linguística e de produzir efeitos de realidade apesar dela. Este sujeito não fala português e nenhum dos atores que o avalia fala a sua língua materna? Este facto é insignificante. Ultrapassando-o, é facilmente possível formar uma opinião médico-científica sobre - sujeito, nomeadamente, é possível avaliar a sua insuficiência neuro-psiquiátrica essencial através de um juízo sobre o coeficiente de inteligência de um indivíduo que não fala português e cuja língua materna nenhum dos envolvidos domina minimamente. O privilégio epistémico de quem exerce poder neste caso é total. É até mesmo possível avaliar o domínio que este sujeito tem da sua própria língua materna sem a conhecer, levando a que se considere - com efeitos de verdade, com consequências de realidade, constrangendo as possibilidades de vida do sujeito - que ele não percebe o que lhe dizem nesta língua que ninguém - para além dele próprio - fala.

Neste caso, é inegável uma total negação de reflexividade ao sujeito diagnosticado, que surge como a priori de toda a classificação e intervenção psiquiátrica dado que não há sequer possibilidade de diálogo entre os envolvidos na interação - aliás, não há sequer possibilidade de comensurabilidade entre eles. A legitimidade intersubjetiva do modelo de intervenção assistencialista-psiquiátrico permite negar toda a reflexividade deste sujeito sem que se tenham condições objetivas que permitam avaliar as suas capacidades. Necessariamente, este caso expressa uma renúncia absoluta ao conhecimento empírico, uma recusa de qualquer enquadramento estrutural e biográfico da vida deste sujeito, que é imediatamente feito transitar para o interior do campo do poder do circuito interinstitucional

107 | Pensando-Revista de Filosofia Vol. 10, № 19, 2019 ISSN $2178-843 x$ 
assistencialista e psiquiátrico sem que haja qualquer possibilidade de redenção, levando a um condicionamento unilateral e draconiano das suas possibilidades de existência.

\section{Conclusão}

Os exemplos discutidos estão longe de corresponder a uma lista exaustiva dos indicadores grotescos de doença mental que orientam as conceptualizações, decisões e ações dos profissionais das instituições assistencialistas e psiquiátricas que intervêm na vida na rua. Muitos outros poderiam ter sido apresentados, mas os casos selecionados apresentam-se como alguns daqueles em que - caráter grotesco da medicalização da vida na rua surge de modo mais nítido.

Em todos os pontos, a desqualificação fundamental de quem exerce um poder medicalizado e medicalizante - assente numa falta de "qualidade intrínseca" que deveria vedar os efeitos de realidade produzidos por tais exercícios de poderz - decorre imediatamente da desancoragem empírica da psiquiatrização da vida na rua. Como foi discutido, o modus operandi do modelo de intervenção dominante sobre a vida na rua confere aos profissionais das instituições referidas a prerrogativa de prescindirem da observação e reflexão rigorosas das propriedades estruturais do modelo societal moderno ocidental contemporâneo e, em particular, da vida na rua. Mas esta prerrogativa estende-se à experiência biográfica que cada sujeito sem-abrigo faz da vida na rua, também ela alvo de uma falta de enquadramento reflexivo. Ainda que a localização estrutural isomórfica coloque perante quem vive na rua um conjunto de obstáculos, privações e negações comuns, cada indivíduo realiza um percurso particular no seio destas similitudes estruturais, levando a que, graças à sua ação própria tal como a fatores aleatórios incontroláveis, certos constrangimentos partilhados sejam minimizados ou maximizados em cada experiência biográfica concreta.

Emergindo de um desconhecimento elementar destas duas dimensões da praxis da vida na rua, a intervenção medicalizada opera através de formas de saber estandardizados e superficiais da área da medicina mental, bem como de intuições mais ou menos (des)informadas de cada um dos profissionais que têm a intervenção a seu cargo, conferindo a cada um deles e, sobretudo, à coletividade que juntos formam, uma margem de manobra considerável nas interpretações e decisões casuísticas que efetivam a cada momento da intervenção.

Na medida em que o exercício do poder parte regularmente duma tal forma de desqualificação apriorística, esta desqualificação não pode ser compreendida como uma casualidade, como um elemento extra de que o exercício do poder na vida na rua poderia prescindir. Antes, a desqualificação fundadora torna-se numa propriedade intrínseca dos exercícios de poder pelos quais a medicalização da vida na rua é concretizada.

27 FOUCAULT, Michel. Les anormaux: Cours au Collège de France, 1974-1975. Paris: EHESS, Gallimard, Seuil, 1999, PP. 12 et passim.

108 | Pensando - Revista de Filosofia Vol. 10, № 19, 2019

ISSN $2178-843 x$ 
Assim, a medicalização deste fenómeno sociopolítico só pode efetivar-se recusando a praxis da vida na rua, nas suas dimensões estruturais e biográficas - o que, por definição, impossibilita qualquer exercício de "imaginação sociológica" pelo qual biografia e estrutura pudessem ser compreensivamente ligadas.28 Rejeitando a observação e a reflexão rigorosas sobre esta praxis, ela é de facto negada por via da naturalização das propriedades estruturais deste modelo societal, incluindo as que compõem a vida na rua, e pela invisibilização do modo como quem é sem-abrigo as vive. Ao negar esta praxis de dominação e privação, o único caminho disponível para o pensamento e para a ação coletiva dos profissionais das instituições incumbidas de intervir na vida na rua é a produção de uma outra praxis, inteiramente assente na menoridade político-ontológica de quem vive na rua, menoridade essa que assume a forma de uma patologização neuro-psiquiátrica que caracteriza a essência de cada indivíduo sem-abrigo e, em si mesma, explica a totalidade dos seus problemas, incluindo, desde logo, o facto de viverem na rua.

Esta produção coletiva de uma outra cosmologia e de uma outra praxiologia da vida na rua, individualmente patológica, estabelece severamente os limites da verdade sobre este fenómeno sociopolítico e sobre cada sujeito que o experiencia. 0 privilégio epistémico da medicalização condiciona as condiçôes de possibilidade de perceção e de enunciação da vida na rua, relegando qualquer praxis alternativa construída por uma outra forma de compreender este fenómeno sociopolítico e de nele agir para o campo do impensável, do indizível, do erro, da falsidade ou da loucura. Deste modo, a medicalização da vida na rua constitui um discurso de verdade cujas barreiras são dificilmente derrubáveis, obstaculizando a formação de uma outra verdade da vida na rua.

Contudo, como os exemplos discutidos deixam claro, estes exercícios de poder medicalizados e medicalizantes não se limitam a estabelecer o campo do verdadeiro. Na medida em que eles partem da desqualificação essencial que é expressa pela ausência de observação, reflexão e enquadramento sociopolíticos deste fenómeno, a medicalização de condutas e ontologias concretas de sujeitos sem-abrigo não pode deixar de assumir, recorrentemente, um caráter ridículo que a torna risível para quem observa a sua efetivação - ainda que o riso provocado pela medicalização da vida na rua só possa surgir como um riso trágico.

Em grande medida, este caráter trágico do riso decorre do poder da verdade (e da sua inextricável relação com a verdade do poder). 0 mesmo privilégio epistémico que permite o estabelecimento da verdade individualmente patológica da vida na rua orienta os procedimentos de intervenção medicalizados e medicalizantes pelos quais as vidas de quem vive na rua são condicionadas. Dado que as definições neuro-psiquiátricas dos sujeitos sem-abrigo expressam a sua menoridade políticoontológica fundamental, os procedimentos de intervenção

28 MILLS, Charles Wright. The Sociological Imagination. New Yorlk: Oxford University Press, 2000 [ed. orig.: 1959]. 
ligados a este poder de definição não podem deixar de constranger consideravelmente as suas vidas. Apesar do exercício do poder nunca ser exclusivamente repressivo e destrutivo, apesar dele ser sempre igualmente produtivo, potenciando formas de ação, discurso e subjetivação,29 o grotesco da medicalização maximiza os seus aspetos constrangedores ao deixar o condicionamento da vida a cargo de sujeitos que a definem a priori como inferior, errada, necessitada de uma tutela benemérita ou coerciva consoante cada caso, sempre com uma dose considerável de arbítrio casuístico da parte de quem possui esta prerrogativa de decisão exógena sobre a vida alheia.

Assim sendo, o grotesco da medicalização da vida na rua é risível na sua tragédia pois a verdade e o riso são indissociáveis do poder de diminuir as possibilidades de vida de quem vive na rua. o poder da verdade da medicalização da vida na rua ancora os procedimentos psiquiátricos pelos quais as vidas dos sem-abrigo são formatadas e limitadas. A anormalidade biomédica destes sujeitos menores é o que, dentro do modelo de intervenção dominante, legitima a coerção mais ou menos explícita pela qual eles são obrigados a frequentar consultas de psicologia e psiquiatra, pela qual são forçados a tomar medicação psiquiátrica, pela qual são tornados pacientes de instituições psiquiátricas em regime de hospital de dia ou são compulsivamente internados em alas psiquiátricas.

\section{Referências}

ALDEIA, João. "A barraca do Ruî: Os laços sociais no fenómeno dos sem-abrigo. 2011. Dissertação (Mestrado em Sociologia) Faculdade de Economia da Universidade de Coimbra, Coimbra.

ALDEIA, João. Governar a vida na rua: Ensaio sobre a bio-tanatopolítica que faz os sem-abrigo sobreviver. 2016. Tese (Doutoramento em Sociologia) - Faculdade de Economia da Universidade de Coimbra, Coimbra.

ARENDT, Hannah. As origens do totalitarismo. Alfragide: Dom Quixote, 2010 [ed. orig.: 1951].

BLAU, Joel. The Visible Poor: Homelessness in the United States. New York e Oxford: Oxford University Press, 1992.

CONRAD, Peter. "Medicalization and Social Control". In: Annual Review of Sociology, n. 18, 1992 , pp. 209-232.

CONRAD, Peter. The Medicalization of Society: On the Transformation of Human Conditions into Treatable Disorders. Baltimore: The John Hopkins University Press, 2007.

CONRAD, Peter; SChNEIDER, Joseph W. Deviance and Medicalization: From Badness to Sickness. Expanded Edition, with

29 FOUCAULT, Michel. História da sexualidade - I: A vontade de saber. Lisboa: Relógio D'Água, 1994 [ed. orig.: 1976]. FOUCAULT, Michel. "É preciso defendera sociedaden: Curso no Collège de France (1975-1976). Lisboa: Livros do Brasil, 2006 [ed. orig.: 1997]. FOUCAULT, Michel. Nascimento da biopolítica. Lisboa: Edições 70, $2010 \mathrm{~b}$ [ed. orig.: 2004]. FOUCAULT, Michel Surveiller et punir: Naissance de la prison. Paris: Gallimad, 2012a [ed. orig.: 1975]. FOUCAULT, Michel Du gouvernement des vivants: Cours au Collège de France, 1979-1980. Paris: EHESS, Gallimard, Seuil, $2012 \mathrm{~b}$. 
a new afterword by the authors. Philadelphia: Temple University Press, 1992 [ed. orig. 1980].

FOUCAULT, Michel. "About the Concept of the "Dangerous Individual" in 19th-Century Legal Psychiatry". In: International Journal of Law and Psychiatry, n. 1, 1978, pp. 1-18.

FOUCAULT, Michel (1980), "Truth and Power". In: GORDON, Colin (org.), FOUCAULT, Michel. Power/Knowledge: Selected Interviews and Other Writings, 1972-1977. New Yorlk: Pantheon, 1980 [ed. orig.: 1977], pp. 109-133.

FOUCAULT, Michel. História da sexualidade - If A vontade de saber. Lisboa: Relógio D’Água, 1994 [ed. orig.: 1976].

FOUCAULT, Michel. Les anormaux: Cours au Collège de France, 1974-1975. Paris: EHESS, Gallimard, Seuil, 1999.

FOUCAULT, Michel. A ordem do discurso: Aula inaugural no Collège de France, pronunciada em 2 de dezembro de 1970. Lisboa: Relógio D’Água, 2005 [ed. orig.: 1971 ].

FOUCAULT, Michel. "É preciso defender a sociedaden: Curso no Collège de France (1975-1976). Lisboa: Livros do Brasil, 2006 [ed. orig.: 1997].

FOUCAULt, Michel. Histoire de la folie à l'âge classique. Paris: Gallimard, 2010 a [ed. orig.: 1972].

FOUCAULT, Michel. Nascimento da biopolítica. Lisboa: Edições 70 , 2010 b [ed. orig.: 2004].

FOUCAULT, Michel. Maladie mentale et psychologie. Paris: PUr, 2011 [ed. orig.: 1954].

FOUCAULT, Michel. Surveiller et punir: Naissance de la prison. Paris: Gallimad, 2012 a [ed. orig.: 1975].

FOUCAULT, Michel. Du gouvernement des vivants. Cours au Collège de France, 1979-1980. Paris: EHESS, Gallimard, Seuil, $2012 \mathrm{~b}$.

GOWAN, Teresa. Hobos, Fustlers and Backsliders; Homeless in San Francisco. Minneapolis: University of Minnesota Press, 2010.

HOPPER, Kim. Reckoning with Homelessness. Ithaca: Cornell University Press, 2003.

LAING, Ronald David. The Divided Self: An Existential Study in Sanity and Madness. London: Penguin, 2010 [ed. orig.: 1960].

LOVELL, Anne M. “Classification and Its Risks: How Psychiatric Status Contributes to Homelessness Policy". In: New England Journal of Public Policy, vol. 8, n. 1, 1992 , pp. 247-263.

LYON-CALLO, Vincent. Inequality, Poverty and Neoliberal Governance. Toronto: University of Toronto Press, 2008 [ed. orig.: 2004].

MATHIEU, Arline. "The Medicalization of Homelessness and the Theater of Repression". In: Medical Anthropology Quarterly, vol. 7, n. 2, 1993, pp. 170-184.

MILLS, Charles Wright. The Sociological Imagination. New York: Oxford University Press, 2000 [ed. orig.: 1959].

111 | Pensando-Revista de Filosofia Vol. 10, № 19, 2019 ISSN $2178-843 X$ 
NYE, Robert A. "The Evolution of the Concept of Medicalization in the Late Twentieth Century". In: Journal of History of the Behavioral Sciences, vol. 39, n. 2, 2003, pp. 115-129.

SCHRAM, Sanford F. After Welfare: The culture of postindustrial social policy. New York: New York University Press, 2000.

SZASZ, Thomas. “The Myth of Mental Ilness". In: Idem. Ideology and Insanity: Essays on the Psychiatric Dehumanization of Man. Syracuse: Syracuse University Press, 1991 [ed. orig.: 1960], pp. 1224.

TERROLLE, Daniel. "Du mirage de l'urgence sociale à la realité anthropologique du terrain: Un bilain de recherche sur les sansabri sur plus d'une décennie". In: Les Cahiers de I'Actif, n. 344/345, 2005, pp. 21-37.

TERROLLE, Daniel; AMISTANI, Carole. "L'alimentation des sansabri: Entre autonomie et dependence", Anthropology of Food, n. 6, 2008. Consultado 22 de março de 2019, disponível em <http:l/journals.openedition.org/aof/4952>.

WASSERMAN, Jason Adam; CLAIR, Jeffrey Michael. At Home on the Street: People, Poverty d a Hidden Culture of Homelessness. Boulder e London: Lynne Rienner Publishers, 2010.

Doutor em Sociologia (Faculdade de Economia/Universidade de Coimbra)

Bolsista de pós-doutoramento no Centro de Ecologia Funcional da Universidade de Coimbra, Portugal E-mail: alvesaldeia@gmail.com 